\title{
Paideusis
}

\section{Beyond a Single World: Pedagogy and Relating in Difference}

\section{Petra Mikulan}

Volume 22, Number 1, 2014

Sexual and Gender Diversity in Schools

URI: https://id.erudit.org/iderudit/1071470ar

DOI: https://doi.org/10.7202/1071470ar

See table of contents

Publisher(s)

Canadian Philosophy of Education Society

ISSN

0838-4517 (print)

1916-0348 (digital)

Explore this journal

Cite this article

Mikulan, P. (2014). Beyond a Single World: Pedagogy and Relating in Difference. Paideusis, 22(1), 100-107. https://doi.org/10.7202/1071470ar

\section{Article abstract}

The central notion of my analysis is that the relational values that are privileged by the feminine, if properly addressed in school, could foster a more inclusive and embodied way of addressing the fundamentally masculine origin of knowledge, curriculum planning as well as daily school rituals and cultures. For this reason I evoke the horizon of sense as captured by Irigaray in her two-ness of the world to designate a positive place for feminine subjectivity in the relational economy of the you and I, her and him. The economy of the placenta is evoked as a new form of connectedness enfolding a new kind of communication in a pedagogical interaction - where multiplicities and differences are privileged over sameness. 'Touch' is given primacy in the formation of a dialogue that does not appropriate but instead evokes the sharing of a desire in the two-ness of the world.
This document is protected by copyright law. Use of the services of Erudit (including reproduction) is subject to its terms and conditions, which can be viewed online.

https://apropos.erudit.org/en/users/policy-on-use/ 


\title{
Beyond a Single World: Pedagogy and Relating in Difference
}

\author{
PETRA MIKULAN \\ Simon Fraser University
}

\begin{abstract}
The central notion of my analysis is that the relational values that are privileged by the feminine, if properly addressed in school, could foster a more inclusive and embodied way of addressing the fundamentally masculine origin of knowledge, curriculum planning as well as daily school rituals and cultures. For this reason I evoke the horizon of sense as captured by Irigaray in her two-ness of the world to designate a positive place for feminine subjectivity in the relational economy of the you and I, her and him. The economy of the placenta is evoked as a new form of connectedness enfolding a new kind of communication in a pedagogical interaction where multiplicities and differences are privileged over sameness. 'Touch' is given primacy in the formation of a dialogue that does not appropriate but instead evokes the sharing of a desire in the two-ness of the world.
\end{abstract}

\section{Introduction}

For centuries we (in the global north) have been developing curriculum to form minds as though abstracted ideas were the primary (if not only) things informing our ways of learning together. But increasingly there is a realization that minds are grounded in particular bodies and those bodies are situated in particular places. Teachers do not hover above students, and so should work to 'touch' them or 'move' them in certain ways because learning is as much about the transfer of affect between the student and the teacher, as it is about cognition. The mind/body dualism in education has for the most part been holistically challenged by PE teachers (Sparkes, 1999) and other theorists who are problematizing the somatic (Beaudoin, 1999), relational (Barlas, 2001), and affective (Game, 1997) aspects of education. Differently put, in recent years "embodiment has provided a basis for recognizing teaching as a fundamentally situated, relational and gestured encounter" (Smith, 2013, p. 65). While helpful for getting a sense of what is called for in order to effectively engage students in learning, much of the literature on embodied teaching risks replicating the problematic appropriation of the other because it does not take seriously the sexuate difference (i.e., man/woman) of the bodies to which it turns, and so leaves the body hanging in discourse.

Given that "the man/woman difference is invoked or conscripted to signify the general opposition of which the logos/mythos couple represent one form" (Le Doeuff, 2002, p. 196), philosophy (as the ordering/disciplining of ideas, i.e., logos), including the philosophy of teaching, has been masculinized, whereas oral culture - and the messy, embodied everyday life in which it is represented today - has been feminized (e.g., as gossip or urban myth). So the turn to embodiment in the philosophy of teaching is, often unwittingly, a turn to the female body - not a literal one, but the fantasy of "a purely negative otherness" that conscripts women, children, people of color, the people, etc. as targets for philosophical penetration, discipline and dismissal (Le Doeuff In Moi, 1987, pp. 92-93). "The feminine, as support and signifier of

(C) Copyright 2014. The author, Petra Mikulan, assigns to Paideusis the right of first publication and educational and non-profit institutions a non-exclusive license to use this document for personal use and in courses of instruction provided that the article is used in full and this copyright statement is reproduced. Any other usage is probibited without the express permission of the author. 
something that, having been engendered by philosophy whilst being rejected by it, operates within it as an indispensable deadweight which cannot be dialectically absorbed" (Le Doeuff, 2002, p. 196). This paper follows Irigaray in fleshing out the feminine body. While risking essentialism, I take seriously the fantasy body that our discipline has inherited, and so choose to give it new meaning that can be used to demystify the troubling gaps that have been opened up between him and her, you and I, truth and experience, without sliding into extreme and unhelpful relativism.

This paper explores the concept of the placental economy, a term coined by Luce Irigaray, as a philosophical trope in order to imagine and flesh out a relational pedagogy that is fluid and full of motion, respecting the other as other in her difference. I propose that in order to come closer to fully respecting the other as other in a pedagogical process, we need to put forward a consciousness of a somewhat novel kind, one that compels a passing in the feminine (I am evoking here the Latin pandere "to spread, unfold, stretch"). A consciousness that is a stretching of the inside out of that which is excluded in the discourse and grammar of western philosophy and epistemology, namely the feminine, embodied in the sensate being of the two-ness of the world. This would entail thinking through where the other as other dwells, how to relate to the other as other accordingly and how to dialogue with her and him in a respectful way - respecting the inseparability of the two while acknowledging their irreducibility to one another.

First, I briefly explore the masculine origin of philosophical thought as is represented in our current educational design in order to set the stage for the discussion of the ways in which the feminine body has become laden with signification while at the same time not given a positive place to dwell. For this reason I evoke the horizon of sense as captured by Irigaray in her two-ness of the world to designate a positive place for her in the relational economy of the you and I, logos and mythos, truth and experience. Third, I suggest that the placenta be seen as a trope that bears the trace of a new kind of communication in a pedagogical encounter with the other. It is evoked to signify a creation of a new intensity that springs forth when the two connect and share a desire. The last part of this paper draws attention to 'touch' as a form of a dialogue that does not appropriate but instead evokes the sharing of a desire in the two-ness of the world. The conclusion of my analysis is that the relational values that are privileged by the feminine, if properly addressed in school, could foster a more inclusive and embodied way of addressing the fundamentally masculine origin of knowledge, curriculum planning as well as daily school rituals and cultures.

\section{Masculine Origin of Philosophical Thought}

Before we can conceive of a pedagogy that would respect otherness in its radical difference, we must expose the present condition of understanding the other that is placed in opposition to ideal masculine transcendental such as the Truth, the Oneness, the objectifiable, the utilitarian, and the fixed. In designing a school curriculum that does not privilege such ideals, we might first look at how theories of knowledge are constructed.

The current curriculum is informed by scientific methodology which fosters a split between the mind and the body that results in a way of relating "to and with the other that is either instinctive or abstract, and remains subjected to realities that are already existing and are external to the relationship itself" (Irigaray, 2008a, p. 145). Within the dominant system of neutral (i.e., unsexed) science, with its unsexed subject, Irigaray argues that the physical and material world is constructed according to the following rules:

The subject and world are similar reflections of each other; deterministic models of thought are applied to the world; the subject and the object are disconnected from each other; the senses are removed from the object (e.g. in privileging vision, other sensory perceptions are forgotten); instrumental forms of knowledge are promoted (e.g. by emphasizing techniques and instruments of scientific enquiry); universal concepts (i.e. the homogenous agreement between diverse objects/events) are proved through methods that prioritize scientific progression over other kinds of relationship. (Irigaray, 1993, pp. 121-122) 
Symbolic forms of thinking can be discerned in curriculum design where formal techniques (backward planning, assessment) are used to represent and displace the complex material and lived and embodied experiences of student's learning and being.

Education fosters efficiency by encouraging competitiveness and segregation. Students' relational desires are undermined by the drive to become the best in a group. In specific ways, claims Irigaray, the dominant educational system is based on a masculine subjectivity that needs objects, "relationships to and with those who are similar, in a group rather than between two individuals" (Irigaray, 2008a, p. 145). Masculine subjectivity forms relationships that are vertical and hierarchical, especially when it comes to sexual difference. She claims that these aspects of his subjectivity "respond to the conditions necessary for a man to emerge from the natural and maternal world" (Irigaray, 2008a, p. 145). He must sever his bodily ties to it and strive toward an ideal realm/future.

Gender dichotomies created in and by philosophy are used to exclude others both within and from philosophy. Philosophy defends itself from a "femininity of chaos" and in doing so makes itself a "discipline":

The discourse we call 'philosophical' produces itself through the fact that it represses, excludes and dissolves, or claims to dissolve, another discourse, other forms of knowledge, even though this other discourse or forms of knowledge may not have existed as such prior to this operation. For philosophical discourse is a discipline, that is to say a discourse obeying (or claiming to obey) a finite number of rules, procedures or operations, and as such it represents a closure, a delimitation which denies the (actually or potentially) indefinite character of modes of thought (even if this character is only potential): it is a barrage restraining the number of possible (acceptable) statements. The simple fact is that philosophical discourse is repressed within it. (Le Doeuff, 2002, p. 195)

In terms of our daily searching for new forms of pedagogy - be it immersed in or giving priority to the cognitive or the material - most of us do not stress enough that the differences of our sexuate being and subjectivity, giving and shaping our experiences of the self, the world, and the other or another, enfold us and take place in fundamentally different ways. Within this philosophy, feminine subjectivity has been misplaced or more accurately, not given a place of dwelling with a positive self-identity.

\section{Beyond a Single World}

Curriculum has not yet recognized and allowed for the becoming of a feminine subjectivity, allowing her positive dwelling in her own culture. In this section I turn to Irigaray to offer something of a corrective because she is attentive to feminine subjectivity and its relational dynamics, its "relations in two with another subject, a subject who is different and who is generally met in a horizontal, and not vertical or genealogical, way" (2008a, p. 145).

Much of Irigaray's work focuses on the sensate experience of women. Sexuate difference for her functions as the ontological foundation for the existence of two different worlds, that is, masculine and feminine, that cannot be reduced to one another; for this reason, many of her texts are considered essentialist. Nevertheless, her recent text entitled Sharing the World offers us a perspective that can stand in place of the feminine as otherness. As she explains: "As soon as I recognize the otherness of the other as irreducible . . . the world itself becomes irreducible to a single world: there are always at least two worlds" (Irigaray, 2008b, p. 22, emphasis original). At first glance it seems as though here too, she is suggesting that the two-ness of worlds allocates two irreducibly different horizons of sense: the masculine and the feminine. Recognizing the sexuate other as other forces sexuate subjects to acknowledge the existence of two irreducible worlds.

But Van Leeuwen (2012) suggests that we should read Irigaray's proposition as sexuate difference being "coextensive with the disclosure of a world that is not one" (p. 480). Reading the phrase "as soon as..." as indicating simultaneity, Van Leeuwen suggests that Irigaray does not force the recognition of otherness as a foundation for the existence of two different worlds. Instead, Van Leeuwen suggests that the appearance of otherness "belongs to the very disclosure of a world, understood as a horizon of sense" (p. 480). This would 
imply, she postulates, that if the appearance of otherness is coextensive with the very disclosure of sense, then otherness as otherness is always already inscribed in the sense of the world without annulling it as radically other to the horizon of sense. Irigaray's invocation of sexuate difference can be understood not as the foundation for a difference of worlds but rather, suggests Van Leeuwen, as its expression and instantiation. In its polyphonous manifestations, sexuate difference designates openness to difference, to the otherness of the other, which is inscribed in the sense of the world as such (Leeuwen, 2012, p. 480). Irigaray's text evokes the question of the transcendental investigation of sense constitution. Van Leeuwen postulates that in Sharing the World, sexuate difference appears as a transcendental condition for the very disclosure of a world that is not one. However, as radically other to and coextensive with the disclosure of a world, the otherness that conditions this horizon of sense is thus "inscribed within the parameters of this transcendental project" (Leeuwen, 2012, p. 481).

The horizon of sense for Irigaray, in its two-ness of the world, is inscribed in the other as other. In her investigation of the constitution of sense, transcendental phenomenology does not fix the meaning of difference. Rather, it reveals the difference (otherness of the other, the new, and the contingent) that is embedded in the constitution of the sense.

Next I would like to build on the horizon of sense as evoked by Irigaray by exploring the placenta in order to designate a different kind of connectedness - one which embraces a kind of communication or relation that engenders with respect for difference.

\section{Placenta Engenders With Respect for Difference}

Until recently, philosophy has guarded the mind/body, literacy/orality split by way of excluding the metaphors of the feminine. The bodily metaphors that were used were those representing the enclosed masculine body, privileging head over the rest of the body. The female body, always already marked, was made to represent that which was excluded (the rest of the body), namely the oral, the sexual and the grotesque - leaky, fluid, pours, and open. Evoking placenta as a way of instantiating what has already been disciplined and excluded might thus be a dangerous move. However, by re-appropriating that which has already been disciplined within philosophy, I can engage the placenta in a double bound vision simultaneously philosophical and embodying. In this section, I will treat the placenta as a trope for what I provisionally call passing in the feminine which evokes a connectedness that strives to be free of the temptation to project onto the other, and to exclude that which is other or another; and that will hopefully embody new forms of dialogue based on sharing a desire with the other rather than appropriating her.

In $J e, t u$, nous, Irigaray writes that the connection between culture and nature, or more specifically biology, has not been examined in great detail. Biology, she claims, has been used to exploit women, but this should not hinder our efforts to rethink this relation between culture and biology (Irigaray, 1992, p. 46). What has served to exploit women, she says, is "a biology interpreted in terms more masculine than feminine" (Irigaray, 2008a, p. 5). There is no need for the paternal law in order to break off the mother-infant fusion because in the womb of the mother herself, nature has "planned a third, the placenta, between the mother and foetus" (Irigaray, 2008a, p. 5). The role of the placenta as regulating third is to invite women to respect a distance, that is, a difference with the other, that nature already respects in women themselves (Irigaray, 2008a, p. 6). Otherness is shared within the self, rather than assimilated, subsumed, excluded, or refuted:

One of the distinctive features of the female body is its tolerance of the other's growth within itself without incurring illness or death for either one of the living organisms. Unfortunately, culture ... has given no interpretation to the model of tolerance of the other within and with a self that this relationship manifests. ... Whereas the female body engenders with respect for difference, the patriarchal social body contracts itself hierarchically, excluding difference. (Irigaray, 1993, p.45)

Women are capable of radical respect for the other's difference. A mother engenders the living endowed "with autonomous existence with respect to" herself (Irigaray, 2008, p. 7). Or as Jones (2011) postulates, 
the placental economy designates a space and a time that is yours and mine, but does not belong to either of us. This relation is a relation of contiguity and contact, rather than substitution or negation. It thus allows differences to remain palpable between two beings who are nonetheless not straightforwardly separable. (p. 161)

The challenge, then, is to engage this model of the placenta as a double bound vision.

Placenta is an organ that connects the two organisms and allows for the tolerance of the foreign within. Interestingly, many non-western cultures perform sacred burial rituals, believing that the placenta is a living being, a deceased sibling, twin, or friend. In a way, it is a third organism, performing all of the vital functions for the fetus (except for the function of the heart) as well as continually modifying the mother body, so that the two can communicate without violently appropriating, killing or subsuming each other. In a sense, the placenta maintains as well as enables the radical difference of the two to remain fully respected while all along creating an interstice, a kind of a vital togetherness of that which is different. I believe that placenta can be used as a model, engendering a new type of grammar and communication. As such, it assumes that what happens between you and I is not imitation, identification, appropriation of difference or violence. Instead, it is a creation of something new (third), a new form of radical connectedness that contracts life in its own rbythm - all the while respecting difference. However, it is important to note here, that such an adoption of the placenta in the philosophic interpretation already performs a form of violence, for the placenta is an organ in and of itself. It is not there just for someone else (mother and baby), as the logic of appropriation would have it. As noted above, placenta continually enables life, but it also is being and life - intensity, and beauty. By way of analogy, problematic as that may be, the connectedness and communication which the placenta continually creates within evokes a new style of togetherness between 'you and I'. Sharing of a desire in the two-ness of the world becomes in this interstice, created each time anew, third. What you and I share between us is a love, a desire, a passion, a divergence, as it is in that one moment at that one time. Like the placenta, it is continually becoming new - with each new pint of blood becoming a fresh breath for the fetus and a new pulsation, a forging forth of the ever-new breath of the mother.

The deep dark inside of my pregnant womb is a living darkness, ripe with fluid movements, rhythmic yet not random. As imaged by Irigaray (1993):

Deeper than the greatest depths your daylight could imagine ... Neither permanently fixed, nor shifting and fickle. Nothing solid survives, yet that thickness responding to its own rhythms is not nothing. Quickening in movements both expected and unexpected. Your space, your time are unable to grasp their regularity or contain their foldings and unfoldings. (p. 13)

This fluidity is not devoid of form; it is a thickness given 'form' by rhythmic movements and pulsations that generate folding and unfolding. These fluid movements, this quickening cannot be reduced to permanently shifting lack. Rather, these movements hold together a space and time that demarcates self and other as fluidly and infinitely exchanging the flow of togetherness:

I caress you, you caress me, without unity - neither yours nor mine, nor ours. The envelope, which separates and divides us, fades away. Instead of a solid enclosure, it becomes fluid: which is far from nothing. This does not mean that we are merged. (Irigaray, 1993, pp. 5960)

The placental economy helps Irigaray in shaping a different form of (female) subject and a different way of generating form. The female subject's maternal body is characterized by fluidity. She is capable of embodying and engendering a new relation between the self and the other as other in a world that is dual, not oppositional.

The placenta as a philosophic trope on the other hand hopefully engenders and embodies the passing in consciousness that embraces the feminine - and sets in motion its perishing. Embraced in difference, even if only in a duration of a moment, a passing in the feminine. A striving to be free of the temptation to project onto the other, to exclude that which is other, and to generalize the other. A being willing to live, write and voice 
out divergence, multiplicities, and differences. An embracing of not knowing, and appreciating the incompleteness of knowledge. An imagining of possible and radically different worlds that we can create and experience between 'you and I'.

\section{Pedagogy in the Two-ness of Worlds}

Cultivating meeting in difference by encouraging a creation of something new in each encounter with the other would be one way of establishing new forms of pedagogy that help students learn to coexist with the other without putting oneself, the other, or another down. Irigaray emphasizes that a way to overcome our instincts of possession, sexual appropriation, subjection, submission and so one, we must learn to dialogue with respect for the different other (Irigaray, 2008a, p. 161). A condition for respectful dialogue is the "desire for the different other can awaken in ourselves" (Irigaray, 2008a, p. xii). Two people awakened in this way question themselves in order to guide one another "on the path towards coming closer in respect for their differences and transcendences." They try to create between them a world they could share: a truth, a knowledge, an art, an ethics which "transcended each one but which they could both share" (Irigaray, 2008a, p. xii). Language is not the only means of "a happy sharing of eros. A cultivation of touch would be more appropriate, but we are still lacking it" (Irigaray, 2011, p. 137). The kind of language of senses/sensing that Irigaray puts forward does not allow for exclusion; it recognizes the other in her fullness of sensate being. As such, the language of senses/sensing takes us beyond the primacy of vision that relegates objects to the passivity of out-there-ness. The dialectic of duality does not privilege one over the other, on a continuum of sameness, but respects the fullness of embodied and lived (sexuate) difference.

I think that exploring what I provisionally call passing in the feminine on the level of that which has been excluded from our philosophical tradition is a viable stepping stone in the long way towards a curriculum that would not imagine students as white masculine subjects, the world as immersed in oneness and knowledge as an object of appropriation; but rather, would truly appreciate the two-ness, the third-ness, the middle and all the other kinds of states of sensate being and experiencing the world. This means that in thinking about knowledge, we should look for new relationships, one of subject-to-subject, rather than subject-to-object. Knowing experienced as subject-to-subject relation would take into consideration the importance of touch. Our relationship to students respecting their otherness would be expressed in an embodied practice of teaching and in using the language of sense or sensings, with words such as co-being, being-in-between, being two, caressing-in-between, grace-full-language, within-touching-without, and so one. It would be a pedagogy that "embraces, caresses and kisses the child, that touches the child, that reaches out and makes the world tangible, that enables the child to be at home in the world, a pedagogy grounded in the gestures of living with children" (Smith, 2013, p. 66). This form of relating one to another would not appropriate the invisible and subsume it into the darkness of our origin. Instead, sharing with the other as other in difference, acknowledging and respecting the relationship that emerges from being awakened in two-ness of the world, would be placed at the center of our pedagogical imaginaries and curriculum designs and practices, we would have to ask questions quite different from the ones shaping our schools today.

\section{Risk of Appropriation}

So cued was Irigaray to the tendency toward appropriation that she anticipated the technical pitfalls that follow from prescriptive approaches to pedagogy. For instance, simply trying to 'touch' one's students is not necessarily to adopt the approach being advocated here, one which proposes respecting and restoring student's own place of dwelling, their individuation in difference that does not consume or subsume her, but instead allows for a sharing of desire.

Irigaray exposes the appropriating force of the dominant theories, in this case, theories of touch. She claims that philosophers who have talked about touch, for example Merleau-Ponty, Sartre or even Levinas 
somehow or other subject touch to sight or to some ideal. They do not allude to caressing as a means of expressing desire while giving back to the other the contours of his or her body, restoring them in this way to their own individuation. (Irigaray, 2011, p. 137)

According to her, these authors compose their notions of caress as "the means of removing identity from the other and so becoming able to possess this other and make use of her, or him, for one's own pleasure, one's own journey" (Irigaray, 2011, p. 137). She thinks these authors cannot imagine sharing a desire with the other as other in an ethical way because of "a lack of cultivation of eros" (Irigaray, 2011, p. 137). She acknowledges their understanding that touch has not been conceived of as a privileged means of entering into relation with ourselves, the other and the world in Western tradition; but she exposes their lack of appreciation of

invisible parts of ourselves regarding touch. They stop at skin. Now if touch remains always invisible as such, some parts of our body that are particularly concerned by eros are also invisible. It is especially the case for women whose mucous membranes are the most sensitive parts affected by an erotic awakening and touching. For lack of a cultivation of touch, the internal mucous parts of the feminine body can be assimilated to the darkness of the maternal origin. (Irigaray, 2011, p. 137)

Once again forgotten, the invisible of the "maternal inside," is assimilated to nothingness. Conceived as such, we cannot share in the most intimate aspects of our erotic loving in two.

The way out for Irigaray is in experiencing self-affection through our two lips touching one another. This can help women (but not only women), to discover a living identity of our own. Uniting the two parts of ourselves through their touching one another, for example, the hands or the eyelids,

we can gather ourselves and this permits us to share with the other without a loss of identity for the one or the other. This represents a path towards a knowledge that does not preclude eros from living on and being cultivated, and our erotic sharings from happening. Such a knowledge is based on selfaffection and it concerns both our external and visible part: the skin, and our internal and invisible part: the mucous tissues, and links them the one to the other while marking a threshold for passing from the one to the other. (Irigaray, 2011, p. 138)

This experiencing of the invisible is different from the darkness of our first dwelling within our mother's bodies and in our relationship with her. This invisibility, argues Irigaray, must find a way into our adult identity in sharing with the other as other. This invisibility cannot be seized or be understood. She believes this to be the reason why the invisible has been excluded from our culture that favors "a rather inquisitive rationalism and naturalism and that has retained of the touch above all the means of grasping and of appropriating" (Irigaray, 2011, pp. 138-139). What is more, even the very people who claim to be material cannot, it seems, agree with the important role that our sexuate bodily morphology plays in the construction of our cultural world:

Now, it is not the same to make love in oneself or outside oneself, to engender in oneself or outside oneself. Neither is it the same to be born from the same gender as one's own or from another gender, and to be able to or not able to engender as one's mother did. These basic original givens determine a psychic and cultural identity peculiar to each sex, whatever could be the differences between a man and a woman. (Irigaray, 2011, p. 77)

In a way, the ultimate question remains: How do I embrace and 'touch' you without appropriating you? What are some of the forms of dialogue, be it wordily or corporeal, that enable me to experience the fullness in your difference? The appropriation of the other as other is only possible in my desire, words and ideas, which have nothing to do with the lived relationship between 'you and I'. Though the other sometimes, like in pregnancy, cannot be seen as separable from me, that does not mean that this other is indistinguishable from me. We are always already two, and here we are.

Although many of the theoretical concepts I have covered thus far would seem at first difficult to put into practice, I would suggest this is predominantly because they are. The sort of pedagogical approach I am 
attempting to think through here would involve a process that finds difficulty in explanation through a brief summary of best practices. Rather, I see this as the continuation of a discussion about the subject and the object of Western pedagogical approaches that is as well quite central to how we think about (our)self and the places we dwell in as Westerners. The theory I have outlined in this paper is thought of more accurate as a beginning in which I would like to situate my further examinations of my teaching experience and my future research inquiry. Having said that, we can begin this pedagogical venture in practice by cultivating strange in

our encounters, between ourselves and between our students, the most fundamental of all passions - a sense of wonder.

\section{References}

Barlas, C. (2001). Learning-within-relationship as context and process in adult education: Impact on transformative learning and social change agency. Retrieved from http:// eric.ed.gov/?id=ED476040

Doeuff, M. L. (2002). The philosophical imaginary. London: Continuum.

Game, A. (1997). Sociology's emotions. Canadian Review of Sociology/Revue Canadienne de Sociologie, 34(4), 385399.

Irigaray, L. (1992). Je, tu, nous: Toward a culture of difference. New York: Routledge.

Irigaray, L. (1993). An ethics of sexual difference. (C. Burke \& G. C. Gill, Trans.) New York: Cornell University Press.

Irigaray, L. (1996). I love to you: Sketch for a felicity within history. New York: Routledge.

Irigaray, L. (2008a). Conversations. London: Continuum.

Irigaray, L. (2008b). Sharing the world. London: Continuum.

Irigaray, L. (2011). Perhaps cultivating touch can still save us. SubStance, 40(3), 130-140. doi:10.1353/sub.2011.0035

Leeuwen, A. van. (2012). Beauvoir, Irigaray, and the possibility of feminist phenomenology. The Journal of Speculative Philosophy, 26(2), 474-484.

Moi, T. (1987). French feminist thought: a reader. Oxford, UK Blackwell.

Smith, S. (2013). Caring caresses and the embodiment of good teaching. Phenomenology \& Practice, 6(2), 65-83.

Sparkes, A. C. (1999). Exploring body narratives. Sport, Education and Society, 4(1), 17-30.

\section{About the Author}

Petra Mikulan is a PhD student in the Faculty of Education at Simon Fraser University and a Research Assistant with the Imaginative Education Research Group. She is interested in imaginative, cultural and feminist approaches to education, subjectivity, sexual difference, irony, corporeality, narrative theory and semiotics. Petra can be reached at pmikulan@sfu.ca 